\title{
Assessing uptake of national HIV screening and testing guidance-Part 1: Awareness, use and usefulness
}

\author{
GP Traversy'1, T Austin'1, J Yau'1, K Timmerman ${ }^{1 *}$
}

\begin{abstract}
Background: In 2013, the Public Health Agency of Canada released the HIV Screening and Testing Guide (the Guide) to support routine HIV screening and testing practices of health care providers in Canada and promote early detection of new HIV cases. Little was known regarding health care providers' awareness and use of the Guide.
\end{abstract}

Objective: To determine Canadian health care providers' awareness, use and perceived usefulness of the Guide.

Methods: An open, anonymous online survey, including questions on awareness, use and usefulness, was developed with stakeholders, validated and pre-tested. It was then disseminated to a convenience sample of health care providers across Canada between June and August 2016.

Results: A total of 1,075 participants representing all Canadian provinces and territories responded to the survey, with the majority being nurses $(54 \%)$ and physicians $(12 \%)$. About two-thirds of respondents $(65 \%)$ were aware of the Guide; of those, approximately half used it. Thirty-five percent of participants were not aware of the Guide, including none of the 173 health care providers in primary care (family/general practice). Among participants who were aware of and used the Guide, over $80 \%$ reported incorporating recommendations from the Guide into their practice and $77 \%$ reported frequently or always being able to find information they were looking for.

Conclusions: The HIV Screening and Testing Guide appears to be very useful for those who are aware of it and use it; however, awareness of the Guide appears to be low in primary care. Although these results need to be interpreted in light of the convenience sample, it suggests broader dissemination efforts may be needed to reach all of the potential users of the Guide.
Affiliation

${ }^{1}$ Centre for Communicable Diseases and Infection Control, Public Health Agency of Canada, Ottawa, ON

\section{${ }^{\star}$ Correspondence: karen.} timmerman@canada.ca

Suggested citation: Traversy GP, Austin, T, Yau J, Timmerman K. Assessing uptake of national HIV screening and testing guidance-Part 1: Awareness, use and usefulness. Can Commun Dis Rep. 2017;43(12):262-6.

https://doi.org/10.14745/ccdr.v43i12a03

\section{Introduction}

In 2014, the Joint United Nations Programme on HIV/AIDS (UNAIDS) announced the global 90-90-90 targets, which sought, by the year 2020, to diagnose $90 \%$ of all HIV-positive individuals, have $90 \%$ of these individuals on antiretroviral therapy (ART) and, of those on ART, have $90 \%$ attain viral suppression (1).

HIV screening and testing is needed in order to make the diagnosis of HIV infection, and, as such, comprehensive HIV screening and testing strategies are essential to reaching the UNAIDS targets. Screening and testing are the first steps to identifying individuals who are HIV-positive and unaware of their infection, which facilitates linkage to care, consequently decreasing morbidity and mortality associated with HIV/AIDS and preventing onward transmission.

At the end of 2014, an estimated 65,040 persons were living with HIV in Canada and an estimated $21 \%$ of those were unaware of their infection (2). This is significant in that those who are unaware of their HIV status are unable to start treatment or take advantage of available support services. In addition, it is estimated that those who are unaware of their infection contribute to $30-50 \%$ of all new infections $(3,4)$.

The Public Health Agency of Canada's (PHAC) HIV Screening and Testing Guide (the Guide) was released in 2013 to facilitate HIV testing in health service delivery settings (5). The Guide provides evidence-based recommendations regarding who, when and how often to screen for HIV, as well as general information about testing procedures.

The Guide is currently available online through PHAC's website and has been printed and distributed through stakeholders and non-governmental organizations, including the Canadian AIDS Treatment Information Exchange (CATIE). Little is known about 
health care providers' awareness and use of the Guide, and whether the Guide is useful to health care providers.

This article describes the results of Part 1 of a larger study assessing the uptake of the Guide. The objective of Part 1 was to evaluate the awareness, use and perceived usefulness of the Guide. The objective of Part 2 was to assess health care providers' knowledge, comfort and clinical practices related to HIV testing (6). The overall study is part of the work underway to inform potential updates of the Guide to support HIV screening and testing practices in Canada.

\section{Methods}

Information related to health care providers' awareness and use of the Guide were collected over a three month period (June-August 2016) as part of a larger anonymous online survey. The Checklist for Reporting Results of Internet E-Surveys was followed where applicable for the reporting of methodology and results (7). The study was approved by the Health Canada and PHAC Research Ethics Board.

\section{Survey design}

The survey was designed in consultation with evaluation, infectious disease and HIV content experts. The design was based on previous PHAC surveys with similar objectives, previous literature on survey design, factors that influence testing behaviour and known barriers and facilitators of testing (8-12). The survey and study protocol were externally peer-reviewed for face validity by an infectious disease physician and an expert in evaluation. Pilot testing of the questionnaire was then conducted with a panel of infectious disease experts prior to full-scale dissemination.

Awareness was assessed by asking participants whether they were aware of the Guide. Those who indicated being aware of the Guide were asked to identify the method (e.g., by email, word-of-mouth, PHAC's website or receiving a print copy of the Guide). Use was assessed by asking participants whether they had used the Guide. If respondents indicated having used the Guide ("users"), they were then asked to report on how often they used it. "Non-users" were defined as those who had not used the Guide, and may or may not have been aware of it. Usefulness was assessed by asking participants how often they were able to find the information they were looking for in the Guide, whether they identified any errors or out of date material in the Guide and whether they regularly incorporated recommendations from the Guide into clinical practice. Further details on these variables, as well as the full survey, are available upon request.

\section{Recruitment and administration}

Participants were recruited to the voluntary survey via a link attached to a bilingual (English and French) email invitation sent to online newsletters/listservs and CATIE. Participants were also recruited by email invitations distributed by contacts of other Government of Canada departments and regional offices. A link to the survey was also sent to 23 associations for health professionals (e.g., physicians, nurses, social workers and community-based service providers). While only three of the professional associations agreed to disseminate the survey (Pacific AIDS Network, Canadian Public Health Association and Canadian AIDS Society), others may have disseminated the survey to their members without informing the research team. Individuals who received the survey via e-mail or newsletter may have also further disseminated the survey among their colleagues and networks so a participation rate cannot be calculated.

The survey was hosted on the Canadian Network for Public Health Intelligence Web Data online surveying tool and was available in English and French. Respondents were provided information related to privacy and data management/storage, length of the survey, purpose of the study and contact information for the principle investigator, prior to providing informed consent to participate. Participation was not incentivized. Participants' responses were included if they were 18 years of age or older, currently practicing and represented health care providers/professionals.

\section{Data management and analysis}

Survey responses were collected in a secure electronic database and then downloaded to a password-protected Microsoft Excel file. Responses were anonymous with no personal identifiers collected (e.g., names, addresses, email addresses or IP addresses). Descriptive statistics were used to calculate response frequencies. Analyses were completed using Microsoft Excel.

\section{Results}

In total, 1,075 health care providers completed the survey. Survey respondents self-identified from all 13 provinces and territories, with the majority from Ontario, British Columbia and Quebec (Table 1). The majority of respondents were nurses (54\%), with physicians (12\%) representing the second most common provider type.

Table 1: Demographics of survey participants-Canada, June-August 2016

\begin{tabular}{|c|c|c|}
\hline Demographics & $\mathbf{n}$ & $\%$ \\
\hline \multicolumn{3}{|l|}{ Province/territory of practice $(n=1,069)$} \\
\hline Ontario & 375 & 35.1 \\
\hline British Columbia & 152 & 14.2 \\
\hline Quebec & 149 & 13.9 \\
\hline Saskatchewan & 107 & 10.0 \\
\hline Manitoba & 91 & 8.5 \\
\hline Alberta & 79 & 7.4 \\
\hline New Brunswick & 30 & 2.8 \\
\hline Nova Scotia & 29 & 2.7 \\
\hline Newfoundland and Labrador & 22 & 2.1 \\
\hline Northwest Territories & 14 & 1.3 \\
\hline Prince Edward Island & 11 & 1.1 \\
\hline Yukon & 7 & 0.7 \\
\hline Nunavut & 3 & 0.3 \\
\hline
\end{tabular}


Table 1: Demographics of survey participants-Canada, June-August 2016

\begin{tabular}{|c|c|c|}
\hline Demographics (con't) & $\mathbf{n}$ & $\%$ \\
\hline \multicolumn{3}{|l|}{ Type of provider $(n=1,071)$} \\
\hline Nurse & 577 & 53.9 \\
\hline Physician & 127 & 11.9 \\
\hline Community health worker & 95 & 8.9 \\
\hline Nurse practitioner & 84 & 7.8 \\
\hline Social worker & 52 & 4.9 \\
\hline Counsellor & 39 & 3.6 \\
\hline Midwife & 8 & 0.7 \\
\hline Medical resident & 0 & 0.0 \\
\hline Other health care provider & 89 & 8.3 \\
\hline \multicolumn{3}{|l|}{ Area of practice $(n=1,055)$} \\
\hline STI/Public Health & 455 & 43.1 \\
\hline Family/General practice & 173 & 16.4 \\
\hline Specialist & 114 & 10.8 \\
\hline Emergency/Urgent care & 27 & 2.6 \\
\hline Other (please specify) & 286 & 27.1 \\
\hline \multicolumn{3}{|l|}{ Setting $(n=1,061)$} \\
\hline Large urban population centre $(100,000+)$ & 564 & 53.2 \\
\hline $\begin{array}{l}\text { Medium population centre (between } 30,000 \text { and } \\
99,999 \text { ) }\end{array}$ & 181 & 17.1 \\
\hline $\begin{array}{l}\text { Small population centre (between } 1,000 \text { and } \\
29,999)\end{array}$ & 234 & 22.1 \\
\hline Rural area $(<1,000)$ & 62 & 5.8 \\
\hline $\begin{array}{l}\text { Geographically isolated/remote (not accessible by } \\
\text { road or only by a dirt/winter road) }\end{array}$ & 20 & 1.9 \\
\hline \multicolumn{3}{|l|}{ Years of practice $(n=1,069)$} \\
\hline$>20$ years & 409 & 38.3 \\
\hline $15-19$ years & 141 & 13.2 \\
\hline $10-14$ years & 149 & 13.9 \\
\hline $5-9$ years & 177 & 16.6 \\
\hline$<5$ years & 193 & 18.1 \\
\hline
\end{tabular}

Abbreviation: $n$, number

Note: Sample sizes varied between $n=1055-1071$ as individual questions were voluntary

Most respondents (43\%) worked in the area of sexually transmitted infections (STIs) and public health. Over $25 \%$ of respondents indicated that their primary area was 'other,' such as corrections, health promotion and public health. Family/general practice (16\%), specialist (10\%) and emergency/urgent care (3\%) made up the remainder of the responses (Table 1). The majority of participants practiced in large urban population centres (53\%). More than a third of providers had been practicing for more than 20 years (Table 1 ).

\section{Awareness}

Approximately two-thirds of participants were aware of the Guide and, of those, half had used it (Figure 1). Nurses were the most aware of the Guide and health care providers who had been practicing for longer periods of time were more likely to be aware of the Guide. None of the health care providers who primarily practice in family/general care reported being aware of the Guide.
Figure 1: Percentage of respondents who are aware of and who use the Guide $(n=1071)$

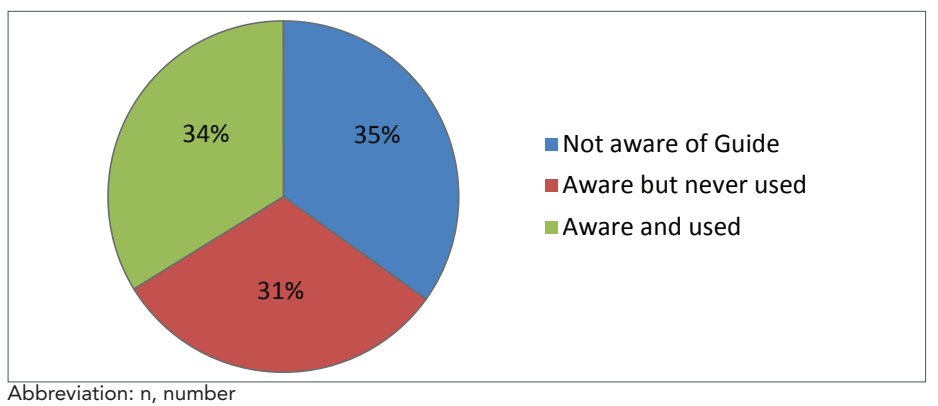

The most common ways of becoming aware of the Guide were via e-mail from PHAC (34\%), a colleague (26\%) or the PHAC website (22\%) (Figure 2).

\section{Figure 2: How respondents became aware of the Guide} $(n=696)$

\begin{tabular}{|l|l|} 
E-mail from the Public \\
Health Agency of Canada \\
Another healthcare \\
professional \\
Public Health Agency of \\
Canada's website \\
Don't know \\
Received a print copy \\
Other (please specify)
\end{tabular}

Abbreviation: $n$, number

\section{Use}

Of 359 users of the Guide, $16 \%$ reported using the Guide frequently (at least once a month), $28 \%$ reported occasional use of the Guide (once every two to three months), 35\% reported rare use of the Guide (once every four to six months) and $21 \%$ reported very rare use of the Guide (less than once a year) and $0.3 \%$ reported never having used the Guide (Figure 3 ). Because they were not aware of the Guide, no health care providers in family/general practice had used it.

Figure 3: Frequency of use of the Guide by those who indicated having used it $(n=359)$

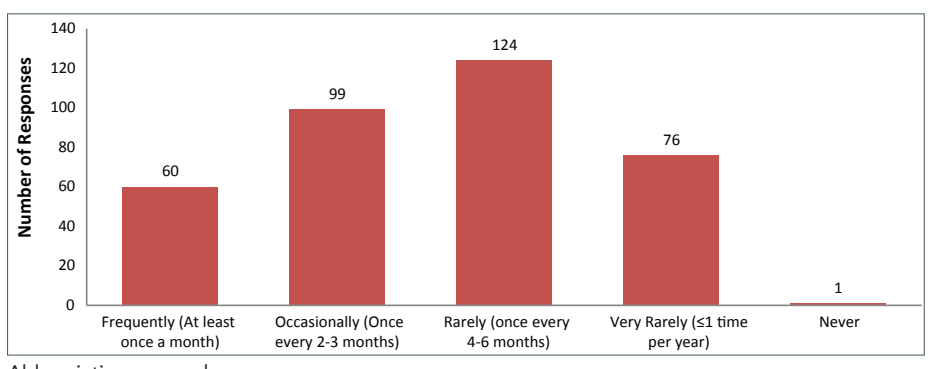




\section{Usefulness}

Of those who used the guide, the majority (84\%) reported that they regularly incorporated recommendations from the Guide in their practice. Most users (77\%) indicated being able to find the information they were looking for at least $75 \%$ of the time (Figure 4). Only 13 users (3.6\%) reported finding errors or out-of-date material in the Guide. This included concerns about the practicality and conciseness of the Guide and the need to update the Guide with respect to new technologies, such as point-of-care testing and pre-exposure prophylaxis (PrEP).

Figure 4: How often users of the Guide are able to find the information they were looking for when using it $(n=358)$

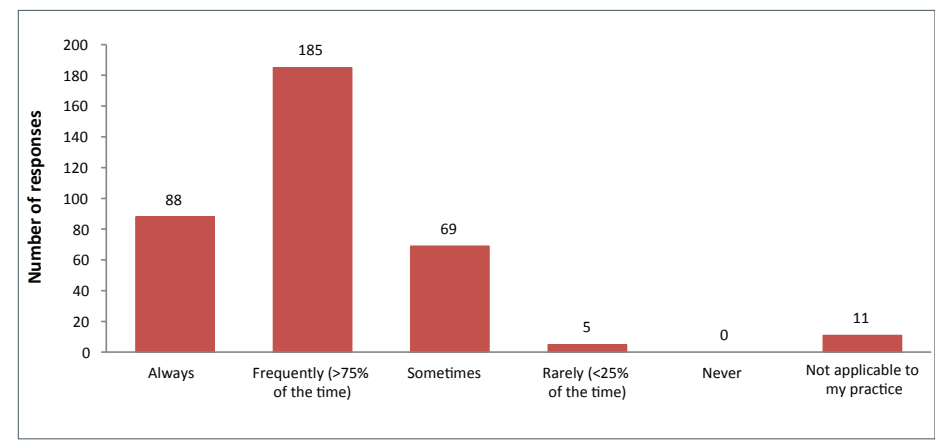

Abbreviation: $n$, number

\section{Discussion}

Overall, the results of this national survey suggest that health care providers have only moderate awareness of PHAC's HIV Screening and Testing Guide but those who had, reported that they regularly incorporated recommendations from the Guide in their practice. It was noted that in a few areas, improvements could be made in the practicality/conciseness of the Guide and incorporating information on new prevention technologies such as PrEP would be useful.

Awareness may have been impacted by the dissemination methods used when first distributing the Guide. Email, the PHAC website and word-of-mouth appear to be effective knowledge dissemination methods as many respondents indicated that they learnt about the Guide through these routes. The avenues of dissemination may have been more likely to target health care providers in the area of sexual health who would be more comfortable with HIV testing than other health care providers.

The strengths of the current study include the geographically representative sample, with respondents from all provinces and territories, and the diverse range of health care providers. Moreover, the survey was comprehensive, covering a number of areas that could be used to update the Guide.

Limitations include the use of a convenience sample, so that the participants may not be representative of all health care providers in Canada and it is not possible to generalize the results to all practitioners in Canada. This may have been particularly true of primary care health care providers. Moreover, the use of self-reported measures with respect to use of the Guide could have been subject to recall bias.

\section{Conclusion}

Awareness of the PHAC's HIV Screening and Testing Guide among health care providers could be improved. Although the current results need to be interpreted in light of the convenience sample, it suggests broader dissemination efforts to reach all of the potential users of the Guide may be needed as part of the overall effort to eliminate HIV in Canada.

\section{Authors' statement}

GT-conceptualization, methodology, data collection and curation, formal analysis, writing-original draft, writing-review and editing, supervision, project administration

TA-methodology, data collection and curation, writing-original draft, writing-review and editing

JY-methodology, data collection and curation, writing-original draft, writing-review and editing

KT-conceptualization, methodology, writing-original draft, writing-review and editing, supervision, project administration

\section{Conflict of interest}

None.

\section{Contributors}

The authors would like to thank the following individuals, in no particular order, for their contribution to this manuscript:

Kelsey Young-formal analysis

Shalane $\mathrm{Ha}$-methodology, reviewing and editing

Jun Wu-methodology, writing-reviewing and editing, project administration

Margaret Gale-Rowe-methodology, writing_reviewing and editing, project administration

Makenzie Weekes—writing — reviewing and editing

Priya Prabhakar-writing_reviewing and editing

Militza Zencovich-methodology

Kanchana Amaratunga-methodology

Courtney Smith-formal analysis

Mandip Maheru-methodology

Ulrick Auguste-methodology

Katie Freer-methodology

Dena Schanzer-methodology, formal analysis

Mary Lysyk-methodology

Katherine Dinner-methodology

Simon Foley-conceptualization, methodology 


\section{Acknowledgements}

The authors would like to acknowledge the input provided by the various contributors throughout the various stages of the project on the survey design, Research Ethics Board submissions, data collection, analysis, and interpretation. Thank you to the team at the Canadian Network for Public Health Intelligence for their help in setting up the survey tool, and to the Health Canada Research Ethics Board. The authors would also like to thank the Expert Working Group of the Canadian Guidelines on Sexually Transmitted Infections for the help with pilot testing the survey, and the various organizations that helped disseminate the survey.

\section{Funding}

The authors have no sources of external funding to declare. This research was supported by the Public Health Agency of Canada.

\section{References}

1. Joint United Nations Programme on HIV/AIDS (UNAIDS). 90-90-90: An ambitious treatment target to help end the AIDS epidemic. 2014. http://www.unaids.org/en/resources/ documents/2017/90-90-90

2. Public Health Agency of Canada. Summary: Measuring Canada's progress on the 90-90-90 HIV Targets. Ottawa; 2016. http://www.healthycanadians.gc.ca/publications/ diseases-conditions-maladies-affections/hiv-90-90-90-vih/ index-eng.php. [Accessed 12/6, 2016.]

3. Skarbinski J, Rosenberg E, Paz-Bailey G, Hall HI, Rose CE, Viall $\mathrm{AH}$ et al. Human immunodeficiency virus transmission at each step of the care continuum in the United States. JAMA Intern Med 2015 Apr;175(4):588-96. DOI (http://dx.doi. org/10.1001/jamainternmed.2014.8180). PubMed (https:// www.ncbi.nlm.nih.gov/entrez/query.fcgi?cmd=Retrieve \&db= PubMed\&list_uids=25706928\&dopt=Abstract).

4. Marks G, Crepaz N, Janssen RS. Estimating sexual transmission of HIV from persons aware and unaware that they are infected with the virus in the USA. AIDS 2006 Jun;20(10):1447-50. DOI (http://dx.doi.org/10.1097/01. aids.0000233579.79714.8d). PubMed (https://www.ncbi.nlm. nih.gov/entrez/query.fcgi?cmd=Retrieve \&db=PubMed\&li st_uids=16791020\&dopt=Abstract).
5. Public Health Agency of Canada. Human Immunodeficiency Virus: HIV Screening and Testing Guide. Ottawa; 2013. http://www.catie.ca/sites/default/files/EN_HIV-ScreeningGuide-2013.pdf

6. Traversy G, Austin T, Yau J, Timmerman K. Assessing uptake of national HIV screening and testing guidance-Part 2: Knowledge, comfort and practice. Can Commun Dis Rep 2017;43(12):266-70. https://www.canada.ca/en/publichealth/services/reports-publications/canada-communicabledisease-report-ccdr/monthly-issue/2017-43/ccdr-volume-4312-december-7-2017/hiv-screening-testing-canada-part-2. html

7. Eysenbach G. Improving the quality of Web surveys: the Checklist for Reporting Results of Internet E-Surveys (CHERRIES). J Med Internet Res 2004 Sep;6(3):e34. DOI (http://dx.doi.org/10.2196/ jmir.6.3.e34). PubMed (https://www.ncbi.nlm.nih.gov/ entrez/query.fcgi?cmd=Retrieve $\& \mathrm{db}=$ PubMed\&list_ uids=15471760\&dopt=Abstract).

8. Rank C, Remis RS, Swantee C, Wu K. Patterns of HIV testing among Ontario physicians. Can J Public Health 2010 JulAug;101(4):294-9. PubMed (https://www.ncbi.nlm.nih. gov/entrez/query.fcgi?cmd=Retrieve $\& \mathrm{db}=$ PubMed\&lis t_uids=21033534\&dopt=Abstract).

9. Smith CR, Pogany L, Foley S, Wu J, Timmerman K, GaleRowe $\mathrm{M}$ et al. Knowledge and counselling practices of Canadian physicians related to antibiotic use and antimicrobial resistance: A two-cycle national survey in 2014/2015. Can Fam Phys. Forthcoming.

10. Skinner K. Developing a tool to measure knowledge exchange outcomes. Can J Program Eval 2007;22(1):49-73.

11. Traversy GP, Austin T, Ha S, Timmerman K, Gale-Rowe M. An overview of recent evidence on barriers and facilitators to HIV testing. Can Commun Dis Rep 2015;41(12):304-12. https://www.canada.ca/en/public-health/services/reportspublications/canada-communicable-disease-report-ccdr/ monthly-issue/2015-41/ccdr-volume-41-12-december-32015-good-news-on-hiv/ccdr-volume-41-12-december-32015-good-news-on-hiv-1.html

12. Seto J, Kapral O, Wong T, Gale-Rowe M, Demers A, Dodds $J$ et al. Differences among Canadian family practitioners by years of practise in uptake of sexually transmitted and blood-borne infections (STBBIs) Clinical Recommendations (STI\&AIDS World Congress 2013 Vienna, Austria). Sex Transm Infect 2013 Jul;89 Suppl 1:A391. DOI (http://dx.doi. org/10.1136/sextrans-2013-051184.1225). 